1 Power, B. A., and Power, R. F., Nature, 194, 1170 (1962).

2 Barthakur, N., and Maybank, J., Nature, 200, 866 (1963).

${ }^{3}$ Evans, L. F., J. Atmos. Sci., 23, 751 (1968).

' Parungo, F. P., and Lodge, J. P., J. Atmos. Sci., 24, 274 (1967).

${ }^{5}$ Schaefer, V. J., Cent. Proc. Roy. Met. Soc., 42 (1950).

6 Power, B. A., and Power, R. F., Final Technical Report to Nat. Sci. Found. on Contract NSF-C 307 (1965).

'Komabayasi, M., and Ikebe, Y., J. Met. Soe. Japan, 39, 82 (1961).

- Blanchard, D. C., Science, 146, 396 (1964).

- Duursma, E. K., Chem. Oceanog., 1 (edit. by Riley and Skirrow, 1963).

${ }^{10}$ Hellebust, J. A., Limnol. and Oceanog., 10, 192 (1965).

${ }^{21}$ Johannes, R. E., and Webb, K. L., Limnol. and Oceanog., 12, 378 (1967).

18 Blanchard, D. C., Science, 146, 396 (1964).

18 Wilson, A. 'T., Nature, 183, 318 (1959).

${ }^{14}$ Wilson, A. T., Nature, 184, 99 (1959).

16 Belton, J. W., Trans. Farad. Soe., 35, 1293 (1939).

16 Evans, L. F., Nature, 211, 281 (1966).

\section{Multiple Charge Transfer Bands in Complexes of Hexafluorobenzene with Aromatic Amines}

Hexafluorobenzene acts as an electron acceptor in forming charge transfer complexes with aromatic amines ${ }^{1}$. In complexes with certain of the amines the charge transfer absorption consists of two bands as shown in Fig. 1 for the hexafluorobenzene- $N, N$-dimethyl-p-toluidine (DMT) complex. Table 1 shows the positions of the two bands and the splitting between them for hexafluorobenzene complexes with DMT, $N, N$-dimethylaniline (DMA) and $N, N$-diethylaniline (DEA).

Table 1. POSITYONS OF THE CHARgE TRANSERR BANDS OF HEXAPLUOROBENZENE COMPLEXES WITH AROMATIC AMINES

$\begin{array}{lccc}\text { Donor } & v_{1} . \mathrm{cr}^{\mathrm{cm}} \mathrm{cm}^{-1} & v_{2} . \mathrm{cr} \mathrm{cm} \mathrm{cm}^{-1} & \Delta v_{\mathrm{Cr}} \mathrm{cm}^{-1} \\ \text { DMA } & 31,650 & 32.570 & 920 \\ \text { DEA } & 31,230 & 32,310 & 920 \\ \text { DMT } & 30,770 & 31,730 & 960\end{array}$

Double charge transfer absorption bands have previously been observed for substituted benzenes with electron acceptors such as tetracyanoethylene and chloranil $^{2-5}$. In such complexes the multiple bands are ascribed to lifting of the degeneracy of the highest occupied benzene $e_{1 g}$ orbitals leading to two ionization potentials for the molecule and two charge transfer (CT) transitions. The splitting between the two absorption peaks $\triangle \bar{v} C T$ for such complexes is very much higher than that observed in the present work. For the complex formed between tetracyanoethylene and $p$ dimethyl. aminoanisole ${ }^{3}$, for example, $\Delta \bar{\nu} C T$ is $14,150 \mathrm{~cm}^{-1}$. Photoionization studies ${ }^{6}$ have shown that the differences between the two ionization potentials in DMA, DEA and DMT are $1.52,1.60$ and $1.74 \mathrm{eV}$, respectively, which should lead to $\Delta \mathrm{i} C T$ being $12-14,000 \mathrm{~cm}^{-1}$ for complexes of these donors. The double charge transfer transitions in hexafluorobenzene complexes cannot therefore be

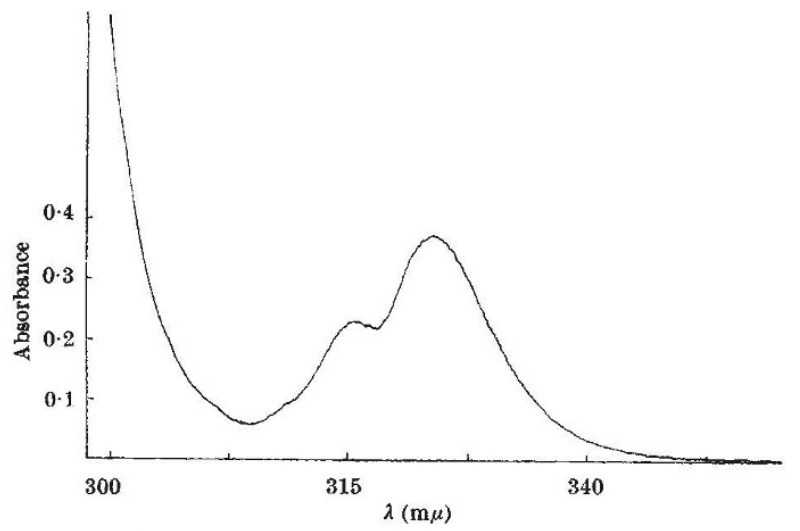

Fig. 1. Absorption spectrum of hexafluorobenzene- $N, N$-dimethyl- $p$ toluidine complex. attributed to this effect. Although the donor levels will be split, the second charge transfer band resulting from this will be at much higher energies and will be obscured by the absorption of the components.

Double charge transfer transitions have also been observed for complexes of tetracyanobenzene $e^{7}$ in which the splitting is again too small to be ascribed to splitting of the donor levels and is attributed to raising of the degeneracy of the lowest unoccupied benzene $e_{2 u}$ levels in the acceptor. In hexafluorobenzene, however, the acceptor levels should still be degenerate.

One explanation of multiple charge transfer bands would be the existence of complexes other than $1: 1$. This seems to be ruled out in this case by the behaviour of the ratio of intensities of the two bands which seems to be significantly unaltered both on dilution and variation of the temperature, although overlapping of the two bands with each other and with the hexafluorobenzene absorption makes accurate determination of the ratio difficult. The heat of association derived from temperature variation of the intensity is, within experimental error, the same for the two bands although different association constants were obtained by application of the Benesi-Hildebrand equation to the two bands. Another possibility - that of charge transfer from both $\pi$ and nonbonding levels on the donor-seems unlikely because the ionization potential of the non-bonding electrons has been estimated to be $9 \cdot 79 \mathrm{eV}$ compared with $7.51 \mathrm{eV}$ for the first ionization potential of the $\pi$ system in DMA ${ }^{6}$. This should give rise to $\Delta \bar{v} \mathrm{C} T$ of about $19,000 \mathrm{~cm}^{-1} \mathrm{com}$ pared with about $1,000 \mathrm{~cm}^{-1}$ actually observed.

The constancy of $\Delta \bar{v} \mathrm{CT}$ on changing the donor seems to imply that in the hexafluorobenzene complexes we are observing multiple bands caused by the acceptor half of the complex. The exact mechanism of the splitting is not clear but there seem to be two possibilities. Either the degeneracy of the two acceptor levels is split by the presence of the donor in the complex, or we are observing vibrational components in the charge transfer band. The former could occur if, as we suggested ${ }^{1}$, hydrogen-bonding forces are involved in stabilization of the complex. This could lead to the components being held in a fixed orientation when the overlap of the two acceptor orbitals with the donor orbital will be different. As for the latter explanation, there is a very strong fundamental vibration at about $1,000 \mathrm{~cm}^{-1}$ in the infrared spectrum of hexa. fluorobenzene ${ }^{8}$ which correlates quantitatively with the $\triangle \bar{v} \mathrm{CT}$ values observed. It is difficult at present to dis. tinguish between these two possibilities, particularly in view of the rather puzzling failure to observe any splitting of the charge transfer band for complexes of hexafluorobenzene with $p$-phenylenediamine derivatives.

T. G. Beaumont

K. M. C. Davis

Department of Chemistry,

University of Leicester.

Received March 25, 1968.

${ }^{1}$ Beaumont, T. G., and Davis, K. M. C., J. Chem. Soc., B, 1131 (1967).

${ }^{2}$ Voigt, E. M., J. Amer. Chem. Soc., 86, 3611 (1964).

${ }^{3}$ Zweig, A., Tetrahedron Lett., 89 (1964).

Orgel, L. E., J. Chem. Phys., 23, 1352 (1955).

${ }^{5}$ Merrifield, R. E., and Phillips, W. D., J. Amer, Chem. Soc., 80, 2778 (1958).

- Baker, A. D., May, D. P., and Turner, D. W., J. Chem. Soc., B, 22 (1968).

'Iwata, S., Tanaka, J., and Nagakura, S., J. Amer. Chem. Soc., 88, 894 (1966).

${ }^{6}$ Steele, D., and Whiffen, D. H., Trans. Faraday Soc., 55, 369 (1959).

\section{Elastic Behaviour of some Polymer Melts}

Quire general continuum-mechanical arguments ${ }^{1}$ show that the "steady state shear compliance" $J_{e}$ of linear visco-elasticity ${ }^{2}$ can be related to the normal stress effects in steady simple shear flow $^{3}$. Consider the usual arrange- 